\title{
Смыслотехники, обращенные к субъектному опыту обучающегося как основе его ценностно-смыслового выбора на примере математики
}

\author{
Ирина В. Абакумова', Наталья Н. Мироненкова ${ }^{2 *}$, Денис В. Пеньков ${ }^{3}$ \\ ${ }^{1}$ Донской государственный технический университет, г. Ростов-на-Дону, Российская \\ Федерация \\ 2 Южно-Российский государственный политехнический университет (НПИ) имени \\ М. И. Платова, г. Новочеркасск, Российская Федерация \\ ${ }^{3}$ Северо-Кубанский гуманитарно-технологический колледж, ст. Кущевская, \\ Краснодарский край, Российская Федерация \\ *E-mail: vin-mir@bk.ru
}

\begin{abstract}
Аннотация
Ввеление. Присвоить ^ичностную, осмысленную направленность процессу обучения возможно в случае применения различных психологических технологий в обучении, способных актуализировать неповторимый субъектный опыт личности. Именно субъектный опыт является основой ценностно-смыслового выбора, выступающего точкой соприкосновения смыслов культуры и смыслов обучающегося. БлагоАаря этому соприкосновению возможно транссрормировать смысловое пристрастие ученика. Новизна исследования заключается в разработке классификации смыс^отехник, обращенных к опыту обучающегося, и их апробацию в рамках учебного процесса с целью повышения мотивации и развития смысловой сореры студентов на занятиях по математике.
\end{abstract}

Методы. В работе использовались: авторская анкета по выявлению субъектной позиции, ценностного отношения учащимися к математике, возможности осуществления выбора в обучении; тест смысложизненных ориентаций (СЖО) в русскоязычной версии ^еонтьева. В исследовании приняли участие 34 обучающихся первых курсов Южно-Российского государственного политехнического университета (г. Новочеркасск).

Результаты. Результаты авторского анкетирования на начальном и конечном этапах педагогического эксперимента показали эфрфективность использования смыслотехник в учебном процессе. Анализ обработки результатов теста смыс^ожизненных ориентаций у студентов говорит о выстраивании учащимся своей собственной субъектной позиции на этапе исслеАования.

ОбсужАение результатов. ПреАложенная классификация психотехник преАставляет интеграцию современных психолого-педагогических технологий, позволяет регулировать в ситуациях выбора чувственно-эмоциональные и мотивационно-ценностные 
выражения обучающихся, раскрывает личностно-смысловой потенциал ^ичности. Внелрение и использование смыслотехник, обращенных к субъектному опыту обучающегося как основе его ценностно-смыслового выбора на примере математики, возможно в случае конструирования соответствующего содержания учебного материала на смысловой основе.

\section{КАючевые слова}

отчужАенность, субъектный опыт, ценностно-смысловой выбор, психологические технологии, психотехники, ассоциативно-образные смыслотехники, творческие смыслотехники, технологии самовыражения, учебная мотивация, педагогический эксперимент

\section{Основные положения}

- снятие отчужАенности в учебном процессе между его субъектами, повышение учебной мотивации, нахожАение смысла учебной Аеятельности возможно в случае актуализации субъектного опыта учащегося или созАания ситуаций выбора на основе этого опыта;

- актуализация субъектного опыта учащихся как основы ценностно-смыслового выбора происходит через эмоционально-чувственный компонент;

- вк^ючение в учебный процесс чувственно-эмоциональных механизмов открытия ^ичностных смыслов, например, смыслотехник, созАаст условия Аля проявления внутренних источников саморазвития и самовыражения учащихся.

\section{Для цитирования}

Абакумова И. В., Мироненкова Н. Н., Пеньков Д. В. Смыслотехники, обращенные к субъектному опыту обучающегося как основе его ценностно-смыслового выбора на примере математики // Российский психологический журнал. 2019. Т. 16, № 2. С. 63-80. doi: 10.21702/rpj.2019.2.4 


\title{
Meaning Techniques Oriented Towards Students' Subjective Experience as the Basis for Their Value-meaning Choices: A Case of Studies in Mathematics
}

\author{
Irina V. Abakumova', Natal'ya N. Mironenkova2", Denis V. Pen'kov ${ }^{3}$ \\ ${ }^{1}$ Don State Technical University, Rostov-on-Don, Russian Federation \\ 2 Platov South-Russian State Polytechnic University, Novocherkassk, Russian Federation \\ ${ }^{3}$ North-Kuban Humanities and Technology Institute, Kuschevskaya Cossack village, Krasnodar \\ Krai, Russian Federation \\ *Corresponding author. E-mail: vin-mir@bk.ru
}

\begin{abstract}
Introduction. The use of various psychological techniques in learning, which are capable of actualizing students' unique subjective experience, may impart a personal and meaningful orientation to the learning process. Subjective experience is a basis for value-meaning choices, which are considered as a point of contact between students' meanings and the meanings of culture. This contact can help students transform their meaning propensities. This paper proposes a new classification for meaning techniques that are oriented towards students' experience and presents the results for their testing in order to increase students' motivation and the development of their meaning sphere in mathematics classes.
\end{abstract}

Methods. This study used (a) the questionnaire developed by the authors to identify students' value attitude towards mathematics, their subjective position, and possibility of choosing in learning and (b) the revised Life Orientation Test (LOT-R, Russian version; D. A. Leontiev). The sample was comprised of 34 first-year students of Platov South-Russian State Polytechnic University (Novocherkassk).

Results. The findings from a questionnaire survey at the initial and final stages of the pedagogical experiment demonstrated the effectiveness of meaning techniques for the educational process. The Life Orientation Test findings speak in favor of students' subjective position at the forming experimental stage.

Discussion. As an integration of modern psychological and pedagogical technologies, the classification of psychotechnics proposed in this study makes it possible to control students' emotions/feelings and values/motivation in choice situations and reveals individuals' personal and meaning potential. The use of meaning techniques oriented towards students' subjective experience as the basis for their value-meaning choices in mathematics classes is possible if teachers construct the educational content on a meaning basis. 


\section{Keywords}

alienation, subjective experience, value-meaning choice, psychological technologies, psychotechnics, associative and image-related meaning techniques, creative meaning techniques, techniques of self-expression, academic motivation, pedagogical experiment

\section{Highlights}

- If teachers actualize students' subjective experience or create choice situations on the basis of this experience they can eliminate alienation between the subjects of educational process, increase students' academic motivation, and find the meaning of educational activity.

- The feeling- and emotion-related component actualizes students' subjective experience as the basis for their value-meaning choices.

- The use of feeling- and emotion-related mechanisms for discovering personal meanings (for example, meaning techniques) creates conditions for manifestations of intrinsic sources of self-development and self-expression among students.

\section{For citation}

Abakumova, I. V., Mironenkova, N. N., \& Pen'kov, D. V. (2019). Meaning Techniques Oriented Towards Students' Subjective Experience as the Basis for Their Value-meaning Choices: A Case of Studies in Mathematics. Rossiiskii psikhologicheskii zhurnal (Russian Psychological Journal), 16(2), 63-80. (in Russ.). doi: 10.21702/rpj.2019.2.4

Original manuscript received 11.01.2019

\section{Введение}

Направленность системы образования не на ученика как субъекта учебного процесса, а в большей степени на сам процесс, порождает отчужденность отношений между субъектами учебного процесса, не способствует раскрытию индивидуального и творческого потенциала учащихся, не решает проблемы целостного развития личности учащегося (Abakumova, Ermakov, \& Kolesina, 2016; Fedotova, Ermakov, Abakumova, \& Latun, 2017; Abakumova \& Zorina, 2017). При этом не всегда обучающиеся могут ответить успехом на возрастающие образовательные требования. В результате возникает отчуждение от учебного процесса, теряется смысл деятельности, утрачивается мотивация, основанная на интересах, смыслах учащегося. Осин (2015) утверждал, что причинами отчуждения служат слабая поддержка учащихся преподавателями, недостаточная ясность требований и нехватка выбора в рамках учебной деятельности. Barnhardt \& Ginns (2014) отмечали, что отчуждение в учебной деятельности проявляется в ее бессмысленности и несоответствии ее содержания собственным интересам учащегося, а причиной порождения отчуждения 
является отсутствие возможностей для творчества и выбора в рамках учебы. Еще в теории марксизма первопричиной отчуждения считались объективно вынужденный характер учебной деятельности и неизбежность выполнения учащимися заданий, не связанных с творчеством, при этом результаты не становились полезными для общества (Sidorkin, 2004). Таким образом, в условиях отчужденной деятельности образующиеся смыслы наличествуют в большей степени на эгоцентричном уровне, что влечет к необратимым последствиям в обществе вплоть до утрачивания ценностей отношений.

Однако присвоить личностную, осмысленную направленность учебному процессу возможно в случае применения различных психологических методов и технологий в обучении, например, психотехник или смыслотехник (Abakumova et al., 2016; Fedotova et al., 2017; Abakumova \& Zorina, 2017), а также сместить акценты на ученика как субъекта процесса, имеющего свой неповторимый субъектный опыт (Мироненкова, 2015). Именно субъектный опыт является основой ценностно-смыслового выбора (см. Мироненкова, 2015 , с. 43), а ценностно-смысловой выбор выступает необходимой точкой сингулярности, точкой соприкосновения смыслов культуры и смыслов обучающегося, и только благодаря такому соприкосновению можно трансформировать смысловое пристрастие ученика и видоизменять смыслы различных уровней (Абакумова, Ермаков и Фоменко, 2013; Абакумова, 2008). В рамках психолого-педагогических исследований достаточно широко представлена проблема субъектного опыта личности как основы ее ценностно-смыслового выбора (Бондаревская, 2000; Осницкий, 1996; Якиманская, 1996; Мироненкова, 2011). По мнению Дьюи (см. Sikandar, 2015), процесс обучения должен планироваться с учетом способностей учащегося, на основе его прошлого опыта. При обучении математике субъектный опыт учащихся выступает как необходимое условие достижения личностных результатов (Далингер, 2016).

Однако до сих пор не было эмпирических данных об изменении ценностно-смысловой сферы в условиях применения в учебном процессе смыслотехник, направленных на самораскрытие субъектного опыта как основы смыслового выбора на занятиях по математике. Цель исследования - изучить смыслотехники, актуализирующие субъектный опыт учащегося и создающие условия для ценностно-смыслового выбора на основе опыта.

Актуализация субъектного опыта учащихся как основы ценностно-смыслового выбора должна происходить только через эмоционально-чувственный компонент (Мироненкова, 2011). Субъектный опыт учащегося состоит из трех компонентов: эмоционально-чувственного, мотивационно-ценностного и содержательно-процессуального. Эмоционально-чувственная сфера человека не имеет четкую структурированную форму, ей характерен смысловой хаос. Она обладает свойствами нелинейности, неустойчивости и неравновесности. 
В силу этого она всегда открыта для развития, особенно в условиях совместного творчества (Кульневич, 2001). Поэтому внедрение в образовательный процесс эмоционально-чувственных технологий и механизмов открытия личностных смыслов, например, смыслотехник, создаст благоприятные условия для вывода сознания из эмоционального хаоса в логические структуры с дальнейшей возможностью развития смысловых структур учащихся.

Смыслотехника как механизм психологического воздействия берет свое начало из психотехники, которая, в свою очередь, рассматривается как система психологических действий и приемов, направленных на конкретный результат. Однако учебный процесс, вышедший за рамки когнитивной направленности и приобретенный направленность личностно-смыслового характера, требует и рассмотрение технологий обучения не только в дидактической плоскости, но и с психологических позиций. Следовательно, смыслотехника как технология обучения становится актуальным орудием, способным к самораскрытию внутреннего мира учащегося и к инициации смысловой деятельности.

В работе Зориной и Зеленова (2016) смыслотехники представляются как современный метод в обучении. Авторы классифицируют их по различным критериям, тем самым выделяя психотехники, сгруппированные по принципу смыслообразности. Именно они в условиях смыслообразования представляют для нас интерес, т. к. способны инициировать смыслы, связанные непосредственно с эмоционально-чувственной сферой человека, взаимодействуют с его ценностями и смыслами. Следовательно, с помощью смыслотехник возможно актуализировать субъектный опыт учащегося, влиять на смысловой выбор личности. Абакумова (Abakumova \& Zorina, 2017) представила следующие подгруппы смыслотехник: смыслотехники, обращенные к субъектному и субъективному опыту; смыслотехники диалога; игротехники; смыслотехники самовыражения; смыслотехники поддержки; смыслотехники творчества; смыслотехники проблемного характера.

В основе всех разновидностей стоит обращение непосредственно к обучающемуся, его жизненному опыту и внутреннему миру. Однако нас интересуют среди них смыслотехники, обладающие как смыслообразующей функцией, так и направленные именно на субъектный (субъективный) опыт учащегося либо создающие условия выбора на основе такого опыта. Следовательно, мы выделили смыслотехники из всего многообразия в соответствии с направленностью на опыт учащегося и спецификой изучения математики (табл. 1). Почти 80 \% опрошенных студентов 1 курса заявили, что математика является труднодоступной дисциплиной. Такой достаточно большой процент подтолкнул нас к идее ориентации учебного процесса к смысловой направленности, в сторону психологических феноменов сознания - на самораскрытие субъектного опыта обучающегося. 


\begin{tabular}{|c|c|c|}
\hline \multicolumn{3}{|c|}{$\begin{array}{l}\text { Классифоикация смыслотехник, направленных на актуализацию субъектного } \\
\text { опыта обучающегося } \\
\text { Table } 1 \\
\text { Classification of meaning techniques oriented towards students' subjective experience }\end{array}$} \\
\hline $\begin{array}{l}\text { Вил } \\
\text { смысло- } \\
\underline{\text { texники }} \\
\text { Meaning } \\
\text { techniques }\end{array}$ & $\begin{array}{l}\text { Пример } \\
\text { Examples }\end{array}$ & 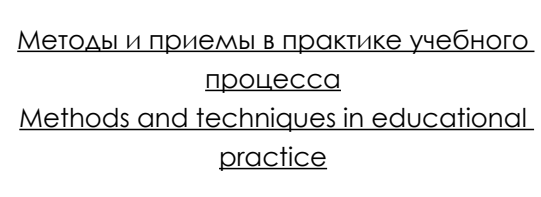 \\
\hline $\begin{array}{l}\text { Ассоци- } \\
\text { ативно- } \\
\text { образные } \\
\text { технологии } \\
\text { Associ- } \\
\text { ative/ } \\
\text { image- } \\
\text { related } \\
\text { techniques }\end{array}$ & $\begin{array}{l}\text { Ассоциирование, } \\
\text { мичностно-смысловое } \\
\text { обобщение, работа } \\
\text { с образами, } \\
\text { с мичностно- } \\
\text { смысловым контекстом } \\
\text { Association, personal- } \\
\text { meaning generalization, } \\
\text { working with images } \\
\text { and a personal-meaning } \\
\text { context }\end{array}$ & $\begin{array}{l}\text { Метол свободных ассоциаций, } \\
\text { перевол теоретического материала } \\
\text { в образный, структурно-логические } \\
\text { схемы, символическое виление, метол } \\
\text { столкновения образов, цветообразы, } \\
\text { смысловое погружение } \\
\text { Free association, translation of the } \\
\text { theoretical content into the image- } \\
\text { related one, structural and logic } \\
\text { schemes, symbolic viewing, the method } \\
\text { of image collision, colour images, } \\
\text { meaning immersion }\end{array}$ \\
\hline $\begin{array}{l}\text { Технологии } \\
\text { само- } \\
\text { выражения } \\
\text { Techniques } \\
\text { of self- } \\
\text { expression }\end{array}$ & $\begin{array}{l}\text { Ситуации выбора, } \\
\text { персонализация, } \\
\text { проживание ситуаций, } \\
\text { саморедлексия } \\
\text { Choice situations, } \\
\text { personalization, } \\
\text { experiencing situations, } \\
\text { self-reflection }\end{array}$ & $\begin{array}{l}\text { Метол вживания (эмпатии), } \\
\text { воображение, метол проектов, } \\
\text { метол своболного выбора, игра, } \\
\text { разотождествление } \\
\text { Empathy method, imagination, project } \\
\text { method, free choice method, play, } \\
\text { disidentification }\end{array}$ \\
\hline $\begin{array}{l}\text { Творческие } \\
\text { (креа- } \\
\text { тивные) } \\
\text { технологии } \\
\text { Creative } \\
\text { techniques }\end{array}$ & $\begin{array}{l}\text { Творческие залания, } \\
\text { сочинения, арт- } \\
\text { технологии, технологии } \\
\text { арт-дилактики, } \\
\text { инсталяяция, инверсия } \\
\text { Creative tasks, essays, } \\
\text { art techniques, } \\
\text { techniques of art } \\
\text { didactics, installation, } \\
\text { inversion }\end{array}$ & $\begin{array}{l}\text { Метол образной картины, } \\
\text { совместная презентация, методы } \\
\text { арт-терапии (музыкотерапия, } \\
\text { библиотерапия, изотерапия, } \\
\text { игротерапия, паркотерапия, } \\
\text { изотерапия и т. А.), орото-проекты } \\
\text { The image-related view method, joint } \\
\text { presentation, art therapy (music therapy, } \\
\text { bibliotherapy isotherapy, play therapy, } \\
\text { park therapy, etc.), photo projects }\end{array}$ \\
\hline
\end{tabular}




\section{Методы}

Для реализации эмпирической части исследования была сформирована практическая база: в ней приняли участие студенты 1 курса факультета инноватики и организации производства образовательного учреждения г. Новочеркасска - Южно-Российского государственного политехнического университета (всего 34 человека). По результатам опроса 27 учащихся $(79,41 \%)$ считают математику труднодоступной дисциплиной, для 5-х она вообще «непосильная наука», и только 2 человека сказали, что с математикой у них не было проблем. Данные опроса подтверждаются их отношением к дисциплине в том, что средний балл единого государственного экзамена при поступлении не превосходил $43 \%$.

С целью определения ценностного отношения к математике учащихся, выявления субъектной позиции, возможности осуществления ими выбора на занятиях, а также условий его самоосуществления на констатирующем этапе нами была создана анкета. Опишем некоторые ответы учащихся. Например, на вопрос «С чем, по Вашему мнению, связаны возникающие проблемы при изучении математики?» ответы показали, что наибольшие проблемы связаны с запоминанием большого количества формул (32,35 \% студентов), с трудностью теоретического материала - у 17,64 \% студентов, у каждого четвертого студента (20,58 \%) - с построением фигур на плоскости, тел в пространстве и их представлением. Немалое количество студентов связывали проблемы с невнимательностью (14,7 \%). Таким образом, непонимание является основной проблемой учащихся. Проблемы с запоминанием большого количества формул связаны с непониманием смысла большинства из них, а именно на каком основании они получены и из чего следуют. В результате учащиеся предпочитают или вынуждены их заучивать, а их количество действительно велико для бессмысленного запоминания; непонимание теоретического материала связано с его отстраненностью от реальной жизни и, как следствие, неспособностью учащихся понять и осмыслить материал.

Таким образом, возникает феномен отчуждения, который является важной психолого-педагогической проблемой в обучении. Например, Кулакова (1997) отмечает, что отчуждение усугубляет социализацию учащегося, создавая чувство оторванности от других людей, одиночества, вследствие чего обучающийся не в состоянии реализовать свой личностный потенциал. Этого мнения придерживается ряд ученых, таких как Матросова, Подходова (см. Кулакова, 1997; Матросова, 2015; Подходова, 2014). Подходова (2014) утверждает, что предупредить отчуждение в процессе обучения возможно в случае проявления субъектности ученика. «Представить свойство субъектности и сделать его доступным изучению и даже диагностике удобнее через анализ более ощутимого образования - субъектного опыта» (Осницкий, 1996, с. 103). 


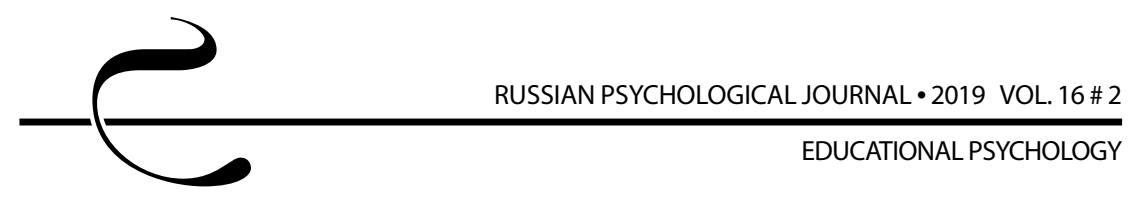

Следовательно, подача материала должна быть ориентирована на субъектный опыт учащихся, теоретический материал и формулы должны нести смысловую нагрузку, применение максимальной наглядности и связи с реальной жизнью, опору на эмоции и чувства учащихся. Одной из задач в применении смыслотехник является компенсация дефицита «эмоциональности» в математике. Как образно выражался российский революционер Ленин (1969, c. 112), «без человеческих эмоций никогда не бывало, нет и быть не может человеческого искания истины».

В работе со студентами с целью выявления их смыслообразований на констатирующем этапе исследования, общего показателя осмысленности жизни, диагностики составляющих смысла жизни был применен тест смысложизненных ориентации (СЖО) в русскоязычной версии Леонтьева.

С учетом специфики курса математики и результатов констатирующего эксперимента в большинстве случаев применялись ассоциативно-образные смыслотехники (Дорф и Мироненкова, 2017). Ассоциативно-образные смыслотехники основаны на установлении связей между поступающей новой информацией и существующим ценностно-смысловым полем учащегося. Характер возникновения ассоциаций спонтанен, хаотичен, не объясним с точки зрения рационального подхода, а сами ассоциации затрагивают чувства и эмоции, они очень личностны и индивидуальны. За счет этого они приближаются к личностным смыслам учащегося. Процесс возникновения ассоциаций в большинстве случаев основывается на субъективном опыте личности.

Возможности данной смыслотехники достаточно широки. В работе Алексеева (1997) продемонстрировано, что ассоциативные связи выступают эффективным средством развития самостоятельности детей и роста познавательных мотивов к предмету; при этом освоение программы курса стало более индивидуальным за счет личностного характера ассоциаций, а учебный материал стал намного доступнее. Его исследования были на примере курса физики, а физика, в свою очередь, является смежной с математикой дисциплиной и относится также к естественнонаучным дисциплинам.

Вместе с ассоциациями образы, впечатанные в структуру сознания человека, играют важную роль в раскрытии смыслов, самораскрытии субъектного опыта учащихся. Образ является неотделимым компонентом опыта человека, его сознания и отношений. Окутанный смыслами и переживаниями, образ относится к сфере чувственности, к пересечению витальных потребностей и познания (Юнг, 1991). Через образ субъект вступает на новую ступень осознанного представления перспективы своего самовыражения. Использование, например, цветообразов как интегративной, смыслообразующей категории в учебном процессе позволит дойти до самых глубинных слоев сознания, 
индивидуализировать процесс обучения на уровне эмоционально-чувственной сферы. Цветообразы представляют собой «сплав» символов, эмоций, смыслов актуального и прошлого опытов обучающегося (Рудакова и Литвинов, 2015; Литвинов и Рудакова, 2016). Отметим, что применение ассоциативно-образных технологий с помощью информационно-коммуникативных средств только усиливает эффективность данной группы смыслотехник в процессе обучения математике (Кухтинова, 2016).

Однако технологии самовыражения и творческие смыслотехники не остались «за кадром». Если человек «видит смысл своей жизни в творчестве как созидании нового, уникального, то его творческая деятельность и будет стремлением к осуществлению смыслового выбора» (Белоконь, 2012, с. 60). Творческая деятельность действительно обогащает смысловую сферу человека. Например, Frankl (1967) выделял ценности, позволяющие человеку выработать жизненную позицию и сделать свою жизнь осмысленной: ценности творчества, ценности переживания и ценности отношения. Frankl отдает преимущество именно ценностям творчества.

К соответствующим смыслотехникам в исследовании мы конструировали и содержание, т. к. узконаправленный, обезличенный учебный материал не будет побуждать к смыслообразованию. Осуществление смыслового развития, а вместе с тем раскрытие субъектного опыта, возможно при погружении в плотную смысловую среду, поликультурное образовательное пространство. Ингредиенты качественного содержания должны обладать способностью влиять на стержневую основу личности ребенка - систему ценностей, а качество технологии заключается в возможности или невозможности замкнуть субъектный опыт обучающегося на объективных реалиях действительности, отраженных в содержании обучения, и тем самым обогатить, изменить, обновить наличные у обучающихся ценности (Абакумова, Ермаков и Кагермазова, 2016).

\section{Результаты}

После завершения курса обучения был проведен второй этап исследования - формирующий эксперимент. Впоследствии мы обработали результаты, полученные по данным групп студентов до и после эксперимента. В исследовании использовались следующие методы: эмпирические, диагностические, методы математической и статистической обработки эмпирических данных.

Результаты анкетирования по выявлению ценностного отношения учащихся к предмету математики, возможности осуществления ими выбора на занятиях, актуализации личного опыта на начальном и конечном этапах педагогического эксперимента показали эффективность использования смыслотехник в учебном процессе. Например, количество учащихся, не имеющих проблем 
при изучении математики, возросло на 52,94\%. Это, на наш взгляд, связано с тем, что теоретический материал для обучающихся в экспериментальных группах был более понятным вследствие его иного представления, ориентации на доступность и возможность практического применения; теоретический материал и формулы стали нести смысловую нагрузку, что сделало их более усваиваемыми без заучивания.

Отвечая на вопрос «Учитываются ли при обучении Ваши способности и возможности?», 65,77\% студентов ответили, что редко или никогда. Это, в свою очередь, является отрицательным моментом в осуществлении ими выбора в процессе обучения, что тормозит, а иногда вообще останавливает процесс смыслообразования. Учет способностей и возможностей учащегося будет способствовать внутренней дифференциации обучения, служащей средством развития индивидуальности. Данное положение было учтено в процессе использования смыслотехник, вследствие чего на заключительном этапе этот показатель улучшился: студентов, ответивших «редко» или «никогда», стало на 14,7\% меньше.

Формирующий этап показал, что для учащихся групп характерны более высокие баллы по большинству субшкал теста смысложизненных ориентаций, чем на констатирующем этапе (табл. 2). Это свидетельствует о наличии у них целей в будущем, о восприятии ими процесса своей жизни как интересного, эмоционально насыщенного, наполненного смыслом, о частичной удовлетворенности отрезка своего жизненного пути, о готовности взять на себя ответственность за строительство своей жизни.

\begin{tabular}{|lcc|}
\hline Таблица 2 & & \\
Результаты исслелования смысложизненных ориентаций обучающихся \\
на констатирующем и фрормирующем этапах эксперимента \\
Table 2 \\
Students' life orientations at the ascertaining and forming experimental stages
\end{tabular}




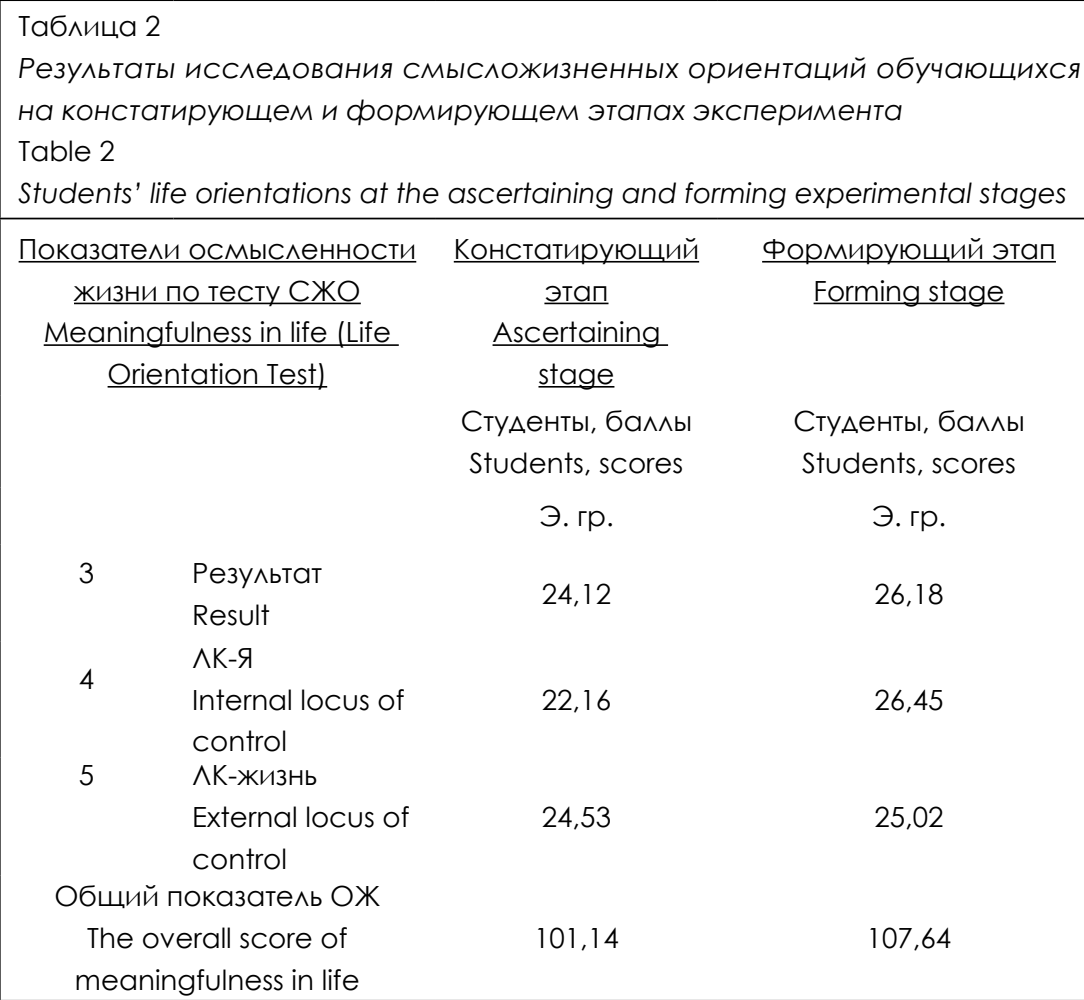

При этом у студентов проявились активная устремленность в будущее, направленность на осознание смысла своей жизни и обладание достаточной свободой выбора для построения своей жизни в соответствии со своими целями, задачами и представлениями о смысле, при этом складывалось обобщенное отношение к жизни, что в целом говорит о наличии субъектной позиции.

В течение обучения курсу математики студенты подвергаются промежуточному компьютерному контролю в форме тестов (всего 6 модулей). Обработка академических показателей групп на формирующем этапе (6-й модуль) показала рост качества обучения дисциплине «математика» с применением смыслотехнических механизмов, направленных на актуализацию субъектного опыта как основы ценностно-смыслового выбора учащихся, по сравнению с констатирующим этапом (1-й модуль). Качественные показатели (оценки «хорошо», «отлично» при пятибалльной системе оценивания) академической успеваемости возросли примерно на 23,5\%. 


\section{Обсуждение результатов}

Включение смыслотехник в обучение преобразует структурную взаимосвязь между учителем и учеником не только на познавательном уровне, но на уровне ценностей и смыслов. Если учащийся усмотрел личностный смысл в каком-то моменте учебной деятельности, то такой выбор рассматривается нами как ценностно-смысловой.

Актуализация опыта обучающегося на основе ценностно-смыслового выбора снимает барьеры отчуждения в учебном процессе между его субъектами. Таким образом, предложенная классификация психотехник демонстрирует интеграцию современных психолого-педагогических технологий, позволяет регулировать в ситуациях выбора чувственно-эмоциональные и мотивационно-ценностные выражения обучающихся, раскрывает личностно-смысловой потенциал личности. Результаты исследования, представленные как сравнительные результаты на этапах констатирующего и формирующего экспериментов, свидетельствуют об общей динамике ценностно-смыслового развития студентов, о проявлении на данном этапе субъектной позиции.

Внедрение и использование смыслотехник в образовательном процессе, обращенных к субъектному опыту обучающегося как к основанию его ценностно-смыслового выбора на примере математики, возможно только при комплексном подходе на смыслообразующей основе с учетом специфики образовательного учреждения, рабочей программы и требований Федерального государственного образовательного стандарта. Использование представленных смыслотехник, ориентированных целиком на ценностно-смысловую сферу учащегося, даст возможность на максимальном уровне предоставить каждому обучающемуся свободу мыслей, чувств, действий в процессе обучения, обеспечивая при этом условия для раскрытия его личностно-смыслового потенциала.

\section{Благодарности}

Исследование выполнено в рамках реализации гранта РФФИ 18-29-22004, «Психологические и генетические исследования предикторов, определяющих поведение пользователей при восприятии Интернет-контентов различной информационной направленности».

\section{Acknowledgments}

This study received grant funding from the Russian Foundation for Basic Research (project no. 18-29-22004, "Psychological and genetic studies of predictors that determine users' behavior when perceiving various Internet content").

\section{Литература}

Абакумова И. В. Смыслодидактика. Учебник для магистров педагогики и психологии. М.: КРЕДО, 2008. 386 с. 
Абакумова И. В., Ермаков П. Н., Кагермазова Л. Ц. Технологии направленной трансляции смыслов в практике учебного процесса: монография. М.: КРЕДО, 2016. 234 с.

Абакумова И. В., Ермаков П. Н., Фоменко В. Т. Новодидактика. Книга 1. Методология и технологии обучения: в поисках развивающего ресурса. М.: КРЕДО, 2013.162 с.

Алексеев В. А. Роль ассоциативных связей в школьном курсе физики: дисс. ... канд. пед. наук. СПб., 1997. 193 с.

Белоконь И. А. Акмеологические особенности смысловой дивергенции как фактора профессионального самоопределения // Российский психологический журнал. 2012. T. 9, № 1. C. 55-61. DOI: 10.21702/rpj.2012.1.5

Бондаревская Е. В. Теория и практика личностно-ориентированного образования. Ростов-на-Дону: Булат, 2000. 351 с.

Далингер В. А. Субъектный опыт учащихся как необходимое условие достижения личностных результатов при обучении математике // Международный журнал прикладных и фундаментальных исследований. 2016. № 2 (часть 3) С. 369-370. Дорф Т. В., Мироненкова Н. Н. Использование ассоциаций в процессе обучения математике // Наука и инновации в XXI веке: Актуальные вопросы, достижения и тенденции развития: сб. ст. победителей II Междунар. науч.-практ. конф. Пенза: МЦНС «Наука и просвещение», 2017. С. 117-120.

Зорина Е. С., Зеленов А. А. Психологические основы смыслотехник как современных образовательных методов // Российский психологический журнал. 2016. T. 13, № 1. C. 76-84. DOI: 10.21702/rpj.2016.1.6

Кулакова Т.Г. Подготовка менеджеров образования к преодолению отчуждения подростков от семьи и школы: дисс. ... канд. пед. наук. Барнаул, 1997. 232 с.

Кульневич С. В. Педагогика личности от концепций до технологий: учебно-практическое пособие. Ростов-на-Дону: Учитель, 2001. 160 с.

Кухтинова А. П. Применение технологии развития ассоциативно-образного мышления на уроках математики с использованием ИКТ и современных гаджетов // Вестник РУДН. Серия: Информатизация образования. 2016. № 3. С. 66-72.

Ленин В. И. Полное собрание сочинений. Издание 5. Т. 25. Март-июль 1914. Москва: Политиздат, 1969. 646 с.

Литвинов К. А., Рудакова И. А. Критерии эффективности технологий, инициирующих смыслообразование в учебном процессе средствами цветообразов // Известия Южного федерального университета. Педагогические науки. 2016. № 3. С. 34-40.

Матросова Ю. С. Предупреждение отчуждения учащихся от школы как проблема современной образовательной практики // Школа будущего. 2015. № 5. С. 162-169. 


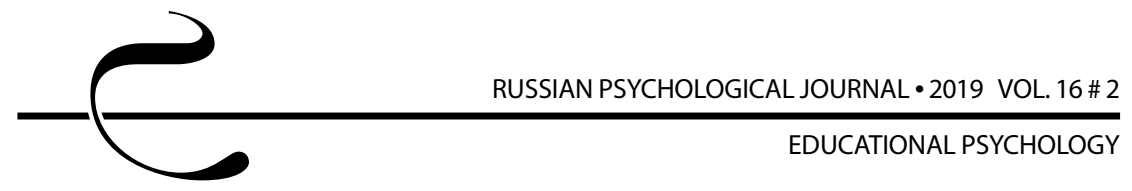

Мироненкова Н. Н. Многоуровневая структура опыта учащегося в контексте смыслообразования // Вестник Адыгейского государственного университета. Серия 3: Педагогика и психология. 2015. № 2 (159). С. 43-51.

Мироненкова Н. Н. Особенности дидактического моделирования ситуаций ценностно-смыслового выбора обучающихся: дисс. ... канд. пед. наук. Ростов-на-Дону, 2011. 190 с.

Осин E. Н. Отчуждение от учебы как предиктор выгорания у студентов вузов: роль характеристик образовательной среды // Психологическая наука и образование. 2015. Т. 20, № 4. С. 57-74. DOI: $10.17759 /$ pse.2015200406

Осницкий А. К. Проблемы исследования субъектной активности // Вопросы психологии. 1996. № 1. С. 5-19.

Осницкий А. К. Психология самостоятельности. М.; Нальчик: Эль-Фа, 1996. 124 с. Подходова Н. С. Субъектный опыт учащихся в преодолении их отчуждения от процесса обучения // Современные проблемы науки и образования. 2014. № 5. URL: http://www.science-education.ru/ru/article/view?id=14774 (дата обращения: 14.05.2019).

Рудакова И. А., Литвинов К. А. Специфика цветообраза как интегративной (смыслообразующей) категории в учебном процессе // Гуманитарные, социально-экономические и общественные науки. 2015. Т. 2, № 11. URL: https://online-science.ru/m/products/Philological\%20and\%20 Pedagogical\%20sciences/gid3436/pg0/ (дата обращения: 14.05.2019).

Юнг К.-Г. Архетип и символ. М.: Реннесанс, 1991. 297 с.

Якиманская И. С. Личностно-ориентированное обучение в современной школе. М.: Сентябрь, 1996. 95 с.

Abakumova I. V., Ermakov P. N., Kolesina K. Y. On analyzing the results of empirical research into the life-purpose orientations of adults of various ethnic identities and religious affiliations // Psychology in Russia: State of the Art. 2016. Vol. 9, Issue 1. P. 155-163. DOI: 10.11621/pir.2016.0111

Abakumova I. V., Zorina E. S. Sense-making techniques in educational process and their impact on the personal characteristics of students // International Journal of Cognitive Research in Science, Engineering and Education. 2017. Vol. 5, № 2. P. 41-46. DOI: 10.5937/IJCRSEE1702041A

Barnhardt B., Ginns P. An alienation-based framework for student experience in higher education: new interpretations of past observations in student learning theory // Higher Education. 2014. Vol. 68, Issue 6. P. 789-805. DOI: 10.1007/ s10734-014-9744-y

Fedotova O., Ermakov P., Abakumova I., Latun V. The peculiarities of updating the interconnection of neuroscience and education in the dissertation discourse // EDULEARN 17 Proceedings. Barcelona, Spain: IATED, 2017. P. 4728-4733. DOI: 10.21125/edulearn.2017.2044 
FrankI V. Psychotherapy and existentialism. New York: Simon and Schuster, 1967. 246 p.

Sidorkin A. M. In the event of learning: Alienation and participative thinking in education // Educational Theory. 2004. Vol. 54, Issue 3. P. 251-262. DOI: 10.1111/j.0013-2004.2004.00018.x

Sikandar A. John Dewey and his philosophy of education // Journal of Education and Educational Development. 2015. Vol. 2, № 2. P. 191-201. DOI: $10.22555 /$ joeed.v2i2.446

\section{References}

Abakumova, I. V. (2008). Meaning didactics: A textbook for master's level psychology and pedagogy students. Moscow: Kredo. (in Russ.).

Abakumova, I. V., Ermakov, P. N., \& Fomenko, V. T. (2013). Methodology and training technologies: Searching a developing resource. In New didactics: Book I. Moscow: Kredo. (in Russ.).

Abakumova, I. V., Ermakov, P. N., \& Kagermazova, L. Ts. (2016). Technologies of the directed translation of meanings in the educational process. Moscow: Kredo. (in Russ.).

Abakumova, I. V., Ermakov, P. N., \& Kolesina, K. Y. (2016). On analyzing the results of empirical research into the life-purpose orientations of adults of various ethnic identities and religious affiliations. Psychology in Russia: State of the Art, 9(1), 155-163. doi: 10.11621/pir.2016.0111

Abakumova, I. V., \& Zorina, E. S. (2017). Sense-making techniques in educational process and their impact on the personal characteristics of students. International Journal of Cognitive Research in Science, Engineering and Education, 5(2), 41-46. doi: 10.5937/IJCRSEE1702041A

Alekseev, V. A. (1997). The role of associative links in the secondary school course in physics (Doctoral dissertation). St. Petersburg. (in Russ.).

Barnhardt, B., \& Ginns, P. (2014). An alienation-based framework for student experience in higher education: new interpretations of past observations in student learning theory. Higher Education, 68(6), 789-805. doi: 10.1007/s10734-014-9744-y

Belokon, I. A. (2012). Acmeological characteristics of meaning divergence as a factor for professional self-determination. Rossiiskii psikhologicheskii zhurnal (Russian Psychological Journal), 9(1), 55-61. doi: 10.21702/rpj.2012.1.5 (in Russ.).

Bondarevskaya, E. V. (2000). Theory and practice of personality-focused education. Rostov-on-Don: Bulat. (in Russ.).

Dalinger, V. A. (2016). Students' subjective experience as a necessary condition for achieving personal results when studying mathematics. Mezhdunarodnyi zhurnal prikladnykh i fundamental'nykh issledovanii (International Journal of Applied and Fundamental Research), 2(3), 369-370. (in Russ.).

Dorf, T. V., \& Mironenkova, N. N. (2017). The use of associations in teaching mathematics. In Science and innovation in the 21st century: Topical 


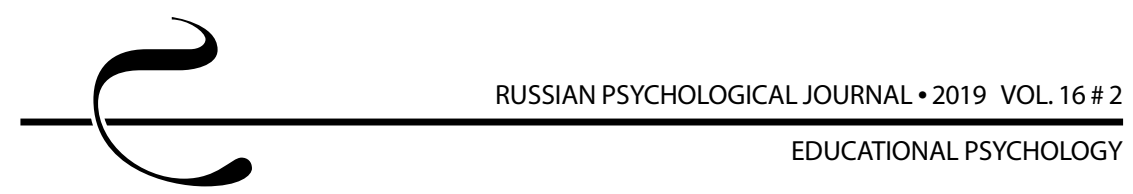

issues, achievements, and trends in development. Proceedings of the 2nd international theoretical and practical conference (pp. 117-120). Penza: Nauka i prosveshchenie. (in Russ.).

Fedotova, O., Ermakov, P., Abakumova, I., \& Latun, V. (2017). The peculiarities of updating the interconnection of neuroscience and education in the dissertation discourse. EDULEARN 17 Proceedings (pp. 4728-4733). Barcelona, Spain: IATED. doi: 10.21125 /edulearn.2017.2044

Frankl, V. (1967). Psychotherapy and existentialism. New York: Simon and Schuster. Jung, C. G. (1991). Archetypes and symbols. Moscow: Rennesans. (in Russ.).

Kukhtinova, A. P. (2016). Using the technology for the development of associative and imaginative thinking at studies in mathematics with information and communication technologies and modern gadgets. Vestnik RUDN. Seriya: Informatizatsiya obrazovaniya (RUDN Journal of Informatization in Education), 3, 66-72. (in Russ.).

Kulakova, T. G. (1997). Education managers training in overcoming adolescent alienation from family and school. (Doctoral dissertation). Barnaul. (in Russ.).

Kul'nevich, S. V. (2001). The pedagogy of personality: From concepts to technologies. Rostov-on-Don: Uchitel'. (in Russ.).

Lenin, V. I. (1969). 1914, March-July. In Collected works (Vol. 25). Moscow: Politizdat. (in Russ.).

Litvinov, K. A., \& Rudakova, I. A. (2016). Criteria for the effectiveness of the technologies initiating meaning-making in the learning process by means of colour images. Izvestiya Yuzhnogo federal'nogo universiteta. Pedagogicheskie nauki (News-Bulletin of Southern Federal University. Pedagogical Sciences), 3, 34-40. (in Russ.).

Matrosova, Yu. S. (2015). Prevention of student alienation from schools as a challenge for modern educational practice. Shkola budushchego (The School of the Future), 5, 162-169. (in Russ.).

Mironenkova, N. N. (2011). Characteristics of the didactic modeling of meaning-value choice situations (Doctoral dissertation). Rostov-on-Don. (in Russ.).

Mironenkova, N. N. (2015). A multilevel structure of students' experience in the context of meaning-making. Vestnik Adygeiskogo gosudarstvennogo universiteta. Seriya 3: Pedagogika i psikhologiya (The Bulletin of the Adyghe State University. Series 3: Pedagogy and Psychology), 2(159), 43-51. (in Russ.).

Osin, E. N. (2015). Alienation from studying as a predictor of burnout in university students: The role of characteristics of the educational environment. Psikhologicheskaya nauka i obrazovanie (Psychological Science and Education), 20(4), 57-74. doi: 10.17759/pse.2015200406 (in Russ.).

Osnitskii, A. K. (1996a). Issues in studying subjective activity. Voprosy psikhologii, 1, 5-19. (in Russ.). 
Osnitskii, A. K. (1996b). Psychology of independence. Moscow; Nalchik: El'-Fa. (in Russ.).

Podkhodova, N. S. (2014). Students' subjective experience in overcoming their alienation from the learning process. Modern Problems of Science and Education, 5. Retrieved from http://www.science-education.ru/ru/article/ view?id=14774 (in Russ.).

Rudakova, I. A., \& Litvinov, K. A. (2015). The specific character of the color image as an integrative (meaning-making) category in the educational process. Humanities, Social-economic, and Social Sciences, 2(11). Retrieved from https:// online-science.ru/m/products/Philological\%20and\%20Pedagogical\%20 sciences/gid3436/pg0/ (in Russ.).

Sidorkin, A. M. (2004). In the event of learning: Alienation and participative thinking in education. Educational Theory, 54(3), 251-262. doi: 10.1111/j.0013-2004.2004.00018.x

Sikandar, A. (2015). John Dewey and his philosophy of education. Journal of Education and Educational Development, 2(2), 191-201. doi: 10.22555/joeed. $\underline{\mathrm{v} 2 \mathrm{i} 2.446}$

Yakimanskaya, I. S. (1996). Personality-focused teaching in modern schools. Moscow: Sentyabr'. (in Russ.).

Zorina, E. S., \& Zelenov, A. A. (2016). Psychological bases for meaning techniques as modern educational methods. Rossiiskii psikhologicheskii zhurnal (Russian Psychological Journal), 13(1), 76-84. doi: 10.21702/rpj.2016.1.6 (in Russ.). 